2. Mackin P, Watkinson HM, Young AH. Prevalence of obesity, glucose homeostasis disorders and metabolic syndrome in psychiatric patients taking typical or atypical antipsychotic drugs: a cross-sectional study. Diabetologia 2005; 48: 215-21.

3. Aranceta-Bartrina J, Serra-Majem L1, Foz-Sala M, Moreno-Esteban B y Grupo Colaborativo SEEDO. Prevalencia de obesidad en España. Med Clin (Barc) 2005; 125: 460-6.

4. Gutiérrez-Fisac JL, Regidor E, Rodríguez Artalejo F. Prevalencia de obesidad en la población adulta española: 14 años de incremento continuado. Med Clin (Barc) 2005; 124: 196-7.

5. Tandon R, Nasrallah HA. Subjecting meta-analyses to closer scrutiny: little support for differential efficacy among second-generation antipsychotics at equivalent doses. Arch Gen Psychiatry 2006; 63: 935-7.

6. Haupt DW. Differential metabolic effects of antipsychotic treatments. Eur Neuropsychopharmacol. 2006; 16 (Supl. 3): S149-55.

7. Wu RR, Zhao JP, Liu ZN, Zhai JG, Guo XF, Guo WB, Tang JS. Effects of typical and atypical antipsychotics on glucose-insulin homeostasis and lipid metabolism in first-episode schizophrenia. Psychopharmacology (Berl) 2006; 186: 572-8 .

8. National Cholesterol Education Program (NCEP) Expert Panel on Detection, Evaluation, and Treatment on High Blood Cholesterol in Adults (Adult Treatment Panel III).Third report of the National Cholesterol Education Program (NCEP) Expert Panel on Detection, Evaluation, and Treatment of High Blood Cholesterol in Adults. Adult Treatment Panel III final report. Circulation 2002; 106: 3143-421.

9. Sackett DI, Haynes RB, Gibson EC, Hackett BC, Taylor DW, Roberts RS, et al. Randomized clinical trial of strategies for improving medication compliance in primary hypertension. Lancet 1975; 1: 1205-07.

10. Goudie AJ, Cooper GD, Halford JC. Antipsychotic-induced weight gain. Diabetes Obes Metab 2005; 7: 478-87.

\section{Zoonosis emergentes}

\section{Sr. Director:}

En los últimos años se ha observado un aumento de enfermedades bacterianas zoonóticas. Presentamos un caso en el que destaca la coinfección aguda y la ausencia de factores epidemiológicos para este tipo de infecciones.

Mujer de 31 años, médico internista, sin hábitos tóxicos, ni antecedentes de interés. Reside en ámbito urbano, sin contacto con animales. No toma leche sin pasteurizar y niega haber realizado viajes recientes o actividades recreativas tipo caza o pesca. Estando previamente bien refiere comenzar hace 15 días con dolor abdominal, fiebre de $39{ }^{\circ} \mathrm{C}$ y diarrea leve, seguido posteriormente de síndrome general con adelgazamiento de $4 \mathrm{~kg}$, y febrícula. La exploración era normal. En la analítica destacaba $\mathrm{Hb} 12 \mathrm{gr} / \mathrm{dl}$, plaquetas $575.000 / \mathrm{mm}^{3}$, leucocitosis $14.840 / \mathrm{mm}^{3}$, con 11.520 neutrófilos/ul, con linfocitos estimulados, VSG: 55 $\mathrm{mm} / 1^{\mathrm{a} h o r a}$, Tasa de Protrombina: 69\%, PCR: 11,2 mg/1, y alteración de pruebas de función hepática (GPT 89 U/L, GOT 57 U/L, GGT 33 U/1, FA 169U/1) con lipasa de 291 U/l. Resto de parámetros generales y estudio de inmunidad resultaron normales. El sedimento de orina presentaba leucocituria (10-12 leucos/campo) y hematuria (7-8 hematies/campo), con cilindros granulosos. En la ecografía abdominal se objetivó engrosamiento y edema del íleon terminal y colon ascendente, con adenopatías adyacentes, líquido en el fondo de saco de Douglas y fosa iliaca derecha, hallazgos que se confirmaron en la tomografía axial computerizada abdominal. Tras realizarse estudios serológicos se demuestra una IgM positiva a Leptospira, y una IgA e IgG positiva a Yersinia enterocolítica, confirmadas posteriormente a las 2 semanas con seroconversión. El resto de serologías resultaron negativas (VHA, VHB, VHC, CMV, VEB, VIH, Salmonella, Herpes, Brucella). El diagnóstico final fue una leptospirosis anictérica y una ileitis por Yersinia, con adenitis mesentérica. La paciente presentó una buena evolución clínica tras tratamiento con doxiciclina 1 semana.

La Leptospirosis en una zoonosis producida por una espiroqueta cuyo reservorio son animales salvajes y domésticos, sobre todo roedores, eliminándose por la orina. El contagio se produce a través del contacto directo con estos animales, o con agua o terrenos contaminados (1). Se caracteriza por afectar a grupos de riesgo con exposición ocupacional o recreativa, como agricultores, pescadores, cazadores, mineros o veterinarios. La mayoría de las ocasiones $(90 \%)$ produce una forma anictérica, como el caso descrito. Asimismo puede producir una forma grave de afectación sistémica (fiebre icterohemorrágica o síndrome de Weil) (24). En nuestro medio es una enfermedad poco frecuente, y en las series publicadas la mayoría de los enfermos presentaban un antecedente epidemiológico característico de esta infección (5).

La Yersinia es otra bacteria zoonótica, cuyo reservorio también son animales como perros, gatos y animales de granja (6). La Yersinia enterocolítica es el tercer patógeno entérico más frecuente tras la Salmonella y el Campylobacter yeyuni, siendo una causa emergente de diarrea en al adulto, pudiendo ocasionar una síndrome apendicular (7).

Nuestro caso es el primero descrito en la literatura médica (MEDLINE) de coinfeccción aguda de estas dos zoonosis, junto a la ausencia de antecedentes epidemiológicos característicos. El hecho de compartir la vía de adquisición, a partir de comida o agua contaminada, obliga a plantearse el papel de la salud pública en las zoonosis emergentes (8-10).

\section{M. Arias Miranda, E. M. Fonseca Aizpuru, M. E. González García, A. G. Barrero López}

Servicio de Medicina Interna. Hospital de Cabueñes. Gijón. Asturias

1. Levett PN. Leptospirosis. Clin Microbiol Rev 2001; 14 (2): 296-326

2. Pumarola Suñé T, Jiménez de Anta Losada MT. Leptospirosis. Medicine 2002; 8 (69): 3688-92.

3. Carrasco I, Arguis P, Miquel R, González-Martín J. Varón de 73 años con fiebre prolongada y alteración de las pruebas hepáticas. Med Clin (Barc) 2007; 128: 111-7.

4. Palaniappan RU, Ramanujam S, Chang YF. Leptospirosis: pathogenesis, immunity, and diagnosis. Curr Opin Infect Dis 2007; 20 (3): 284-92.

5. Menéndez Calderón M.J, Nuño Mateo FJ, Fonseca Aizpuru EM, Oteroa L. Leptospirosis en Asturias. An Med Interna 2005; 22: 548-9.

6. Marcos Sánchez F, Albo Castaño MI, del Valle Loarte P, Joya Seijo D. Infecciones por Yersinia. Medicine 2006; 09: 3449-55.

7. Feeney GF, Kerlin P, Sampson JA. Clinical aspects of infection with Yersinia enterocolítica in adults. Aust N Z J Med 1987; 17 (2): 216-9.

8. Rodríguez-Vidigal FF, Vera-Tomé A, Muñoz-Sanz A. Leptospirosis. Medicine 2006; 09: 3571-6.

9. Meslin FX, Stöhr K, Heymann D. Public health implications of emerging zoonoses. Rev Sci Tech 2000; 19 (1): 310-7.

10. Higgins R. Emerging or re-emerging bacterial zoonotic diseases: Bartonellosis, leptospirosis, Lyme borreliosis, plague. Rev Sci Tech 2004; 23 (2): $569-81$. 